\title{
NSW FALL INJURY INDICATORS-15 YEAR PROJECTIONS
}

\section{Rebecca Mitchell}

Injury Prevention and Policy Unit

NSW Department of Health

\section{Jerry Moller}

New Directions in Health and Safety

Falls are a major cause of morbidity and mortality in older people. In the financial year 1997-98, 16,951 people aged over 65 were hospitalised in NSW for more than one day due to a fall, which represents 14 per cent of all hospitalisations due to injury. ${ }^{1}$ This article describes a 15 -year projection of injury due to falls in NSW.

As individuals retire, they often change residence. Many retirees seek to live in a warmer climate near the coast. Some rural residents move to larger towns and cities to be closer to health and other services. Fall injury prevention and services, and associated health care resources, need to be located where older people choose to live.

The Injury Prevention and Policy Unit of the NSW Department of Health has attempted to identify where resources regarding fall injury prevention should be allocated in the next 15 years. To achieve this, information for each area health service, and each Statistical Local Area (SLA), has been generated regarding:

- population projections by age group;

- fall-related bed day projections by age group;

- fall-related health service costs and utilisation.

There are several ways of measuring the effect of falls. The indicators chosen for this projection are likely to be consistently measurable over time; however, they should not be taken as absolute measures of demand or cost.

An overview of the population projections for each area health service show that the population of some metropolitan area health services, which already have large populations of individuals aged 60 years or older-such as South Western Sydney, Northern Sydney, and SouthEastern Sydney-will continue to increase.

The projections suggest that the Wentworth and Western Sydney Area Health Services will have the greatest increase in the proportion of the population aged 60 years or older, when compared with the other area health services.
Utilising the fall-related bed day projections at the SLA level within the Western Sydney Area Health Service, the greatest bed day demand for fall injury will occur for those aged 75 years or older in the Baulkham Hills, Blacktown, and Parramatta SLAs. Having this type of local information available for each area health service should assist in the planning and provision of future fall injury prevention services.

As retirees relocate over the next 15 years, some area health services along the NSW coast and regional centres will have an influx of individuals aged 60 years or older. For example, projections of bed day demand in the Hunter Area, which has several coastal communities, suggest that the greatest bed day demand for fall injury will occur for those aged 75 years or older in the Cessnock, Lake Macquarie, Maitland, 'outer' Newcastle (NewcastleRemainder), and Port Stephens SLAs. The most dramatic increase will occur in the Port Stephens SLA, with a 50 per cent increase in bed day demand for those aged 75 and over between 2001 and 2016. In the Macquarie Area Health Service, which has two regional centres, the greatest bed day demand for fall injury will occur for those aged 75 years or greater in the Dubbo SLA and to a lesser extent in the Mudgee SLA.

There will also be some smaller area health services where an increase in the proportion of those aged 60 years or greater will occur in particular SLAs. For example, in the Far West Area Health Service, the greatest bed day demand for fall injury will occur for the 60 to 74 year olds in the Bourke SLA, and for those aged 75 years or greater in the Broken Hill SLA.

The NSW Fall Risk Indicators for each area health service and each SLA are available at www.health.nsw.gov.au/public-health/healthpromotion/improve/injury/fallinjuryindicators/ injuryindicators.html.

\section{REFERENCES}

1. Public Health Division. The health of the people of NSWReport of the Chief Health Officer. NSW Department of Health: Sydney, 2000. 